\title{
What are hot and what are not in an urban landscape: quantifying and explaining the land surface temperature pattern in Beijing, China
}

\author{
Wenhui Kuang • Yue Liu • Yinyin Dou • Wenfeng Chi • Guangsheng Chen • \\ Chengfeng Gao $\cdot$ Tianrong Yang $\cdot$ Jiyuan Liu $\cdot$ Renhua Zhang
}

Received: 1 July 2014/Accepted: 21 November 2014/Published online: 6 December 2014

(C) Springer Science+Business Media Dordrecht 2014

\begin{abstract}
Context Understanding how landscape components affect the urban heat islands is crucial for urban ecological planning and sustainable development.

Objective The purpose of this study was to quantify the spatial pattern of land surface temperatures (LSTs) and associated heat fluxes in relation to land-cover types in Beijing, China, using portable infrared thermometers, thermal infrared imagers, and the moderate resolution imaging spectroradiometer.

Methods The spatial differences and the relationships between LSTs and the hierarchical landscape structure were analyzed with in situ observations of surface radiation and heat fluxes.

Results Large LST differences were found among various land-use/land-cover types, urban structures, and building materials. Within the urban area, the mean LST of urban impervious surfaces was about $6-12{ }^{\circ} \mathrm{C}$ higher than that of the urban green space.
\end{abstract}

W. Kuang $(\bowtie) \cdot$ Y. Liu · W. Chi · T. Yang ·

J. Liu $\cdot$ R. Zhang

Key Laboratory of Land Surface Pattern and Simulation, Institute of Geographic Sciences and Natural Resources

Research, Chinese Academy of Sciences, Beijing 100101,

China

e-mail: kuangwh@igsnrr.ac.cn

Y. Dou

State Key Laboratory of Earth Surface Processes and

Resource Ecology, Beijing Normal University,

Beijing 100875, China
LSTs of built-up areas were on average $3-6{ }^{\circ} \mathrm{C}$ higher than LSTs of rural areas. The observations for surface radiation and heat fluxes indicated that the differences were caused by different fractions of sensible heat or latent heat flux in net radiation. LSTs decreased with increasing elevation and normalized difference vegetation index.

Conclusions Variations in building materials and urban structure significantly influenced the spatial pattern of LSTs in urban areas. By contrast, elevation and vegetation cover are the major determinants of the LST pattern in rural areas. To alleviate urban heat island intensity, urban planners and policy makers should pay special attention to the selection of appropriate building materials, the reasonable arrangement of urban structures, and the rational design of landscape components.

Keywords Urban heat island - Land surface temperature · Urban landscape · Land-use/land-cover . MODIS · Portable infrared thermometer

\footnotetext{
W. Chi

College of Resources and Environment, University of Chinese Academy of Sciences, Beijing 100049, China

G. Chen

Environmental Sciences Division, Oak Ridge National Laboratory, Oak Ridge, TN 37831, USA

C. Gao

Southwest University of Science and Technology, Mianyang 621010, China
} 


\section{Introduction}

Urban microclimate alteration is often characterized by urban heat islands (UHIs), which are defined as the phenomenon where atmospheric and land surface temperatures (LSTs) are higher in urban areas than in surrounding rural areas (Oke 1995; Voogt and Oke 2003). UHIs are thought to be one of the most prominent environmental issues related to urban climate and the sustainable development of cities (Oke 1984; Grimm et al. 2008; Alberti 2009; Wu 2010; Pickett et al. 2011; Wu 2013). The UHI effect is mainly caused by the difference in surface physical properties, urban structure, land cover, land use, anthropogenic heat sources and air pollution (Oke 1982; Streutker 2003; Buyantuyev and Wu 2010). The land surface physical properties (e.g., albedo, emissivity, thermal capacity, thermal conductivity, and thermal inertia) of various land-cover types (e.g., impervious surface, vegetation, and water) are significantly different, which could result in LST heterogeneity. Indeed, the LST difference among various intraurban land surfaces may be as large as, or even larger than, the urban-rural difference (Buyantuyev and $\mathrm{Wu}$ 2010). Accordingly, the intra-urban LST variations result largely from the different physical properties, including urban structure, which refers to the spatial dimensions of buildings and street canyons; urban land-cover, including impervious surfaces, green space, bare soil, and water; urban fabric, which refers to building materials; and urban metabolism, including anthropogenic sources of water, heat, and pollutants (Oke 2004). It is important to understand and quantify UHIs associated with a hierarchical landscape structure so that the residential environment of urban dwellers might be improved (Wu 2010).

Urban landscape patterns, including landscape composition (i.e., the fraction or abundance of physical properties) and configuration (i.e., the spatial arrangement of physical properties), are closely related to LST (O'Neill et al. 1988; Li et al. 2011; Connors et al. 2013; Wu 2014). Landscape composition identifies the abundance and variety of land-cover types without considering their spatial characteristics, for example, the impacts of vegetation fraction and impervious surface area on LST (Zhang et al. 2008; Zhou et al. 2011a, b; Zhang et al. 2013). Cities are characterized by large fractions of impervious surfaces composed of concrete, asphalt, brick, pebbles or aggregates which absorb and store radiation during the daytime and slowly release heat during the night (Buyantuyev and Wu 2010; Kuang et al. 2014). Furthermore, landscape composition directly affects UHI through the modification of surface physical properties. The selection of building materials will greatly influence the land surface physical properties, such as albedo (Oke 1984). For example, lightercolored building materials generally have higher albedo and absorb less heat, while darker materials generally absorb more heat than lighter materials and result in higher LSTs. Landscape configuration represents the spatial arrangement or distribution of landcover features within landscape heterogeneity, and plays an important role in UHI due to the effect of surface fluxes. Therefore, it is crucial to consider both landscape composition and configuration in urban design to mitigate potentially harmful LST changes across urban areas (Wu 2010).

Currently, there are three major approaches for studying UHI including air temperature measurement from meteorological stations, LST retrieved from satellite remotely sensed images, and in situ observations of surface radiative temperature using portable infrared thermometers or thermal infrared imagers. The LST obtained from meteorological stations can reflect differences in atmospheric temperature over long periods; however, the extrapolation of the station data to region level is often biased by the distribution of the meteorological stations (Oke 1982; Chen and Pan 1997; Ouyang et al. 2007; Yang et al. 2011). LST retrieved from remotely sensed products can be used to quantitatively represent spatial characteristics of LST at various urban surfaces, but is limited by low temporal resolution and shorter data records (Dale and Jeffrey 1999; Ouyang et al. 2007) and by difficulty in validating the retrieved results using ground-based measurements at different spatial scales (Mao et al. 2005; Ji et al. 2006; Wang and $\mathrm{Hu} 2006$; $\mathrm{Li}$ et al. 2013). Ground-based measurements using thermal infrared instruments at a specific time and location can provide timely and accurate LST for specific land-use and land-cover types (Wang et al. 2011).

During the past two decades, a few studies addressed the phenomena of UHI or the relationship between landscape patterns and LST in Beijing. Based on landsat thematic mapper (TM) images and a regression tree model, Xiao et al. (2007, 2008) estimated the spatial distribution of LST in Beijing 
and explored its relationship with the proportion of impervious surface. Li et al. (2012) revealed the relationship between the proportion of green space and LST based on Landsat TM images, and indicated that $10 \%$ increase in green space could result in $0.86{ }^{\circ} \mathrm{C}$ decrease in LST. Based on air temperature data from 20 weather stations during a 41 year period (1960-2000), Lin and Yu (2005) indicated that UHI intensity in Beijing had increased significantly with the accelerated urbanization, with a trend of $+0.31{ }^{\circ} \mathrm{C} /$ decade. Ji et al. (2006) estimated the impact of urban growth on UHI in Beijing based on MODIS LST products. The frequency of extreme high-temperature events in Beijing increased significantly over the last decade (Chen and Pan 1997). Impervious surface area is positively correlated with UHI, as LST has increased by approximately $9.18{ }^{\circ} \mathrm{C}$ due to replacement of natural surfaces with impervious surfaces (Xiao et al. 2007). These studies suggest that LSTs in Beijing have significantly changed as the process of urbanization replaces natural vegetation with impervious surfaces.

Although several studies referenced above address the spatial and temporal patterns of LST in Beijing, no studies investigate the LST and surface energy fluxes for various landscape components. Through implementation of synchronized LST observations using portable infrared thermometers, thermal infrared imagers, and improved MODIS data, our specific objectives were to (1) quantify the LST and energy fluxes over various land-use/land-cover types, as well as building materials based on ground-based observations, (2) improve MODIS retrieval parameters to retrieve and estimate regional LST along an urban-rural gradient, and finally (3) assess the impacts of different land surface physical properties and urban structures on the magnitude and spatial distributions of LST.

\section{Methods}

In this study, we adopted a synchronized approach to explore LST of different land surfaces by integrating remotely-sensed data with ground-based observations at local and regional scales. We measured LST of various land surfaces using thermal infrared imager and portable infrared thermometer at multiple observation sites. Using the ground-based observations, we calibrated the parameters of a MODIS LST algorithm and analyzed regional differences of LST for various land-use/land-cover types, urban building materials, and urban structures.

\section{Ground-based measurements of LST}

We used the portable infrared thermometer and thermal infrared imagers to measure LST. The portable infrared thermometer used in this study is the MAX4 $4^{\mathrm{TM}}$ produced by Raytek Inc. (Germany). For this instrument, the range of temperature measurement is $-30-900{ }^{\circ} \mathrm{C}$, the measurement precision is $\pm 0.75 \%$ or $1{ }^{\circ} \mathrm{C}$, the response time is $250 \mathrm{~ms}$, the spectral response is $8-14 \mu \mathrm{m}$, the optical resolution is $60: 1$, and the environmental temperature of operation is $0-50{ }^{\circ} \mathrm{C}$ (Wang et al. 2011). The thermal infrared imager used in this study is a Forward Looking Infrared Radiometer (FLIR) T425 model manufactured by FLIR Systems Inc. (USA). The field of view (FOV) of the device is $25^{\circ} \times 19^{\circ} / 0.4 \mathrm{~m}$, the thermal sensitivity is less than $0.05^{\circ} \mathrm{C}$, the wavelength range is $7.5-13 \mu \mathrm{m}$, the infrared image resolution is $320 \times 240$ pixels, the temperature range is $-20-1,200{ }^{\circ} \mathrm{C}$, and the measurement precision is $\pm 2 \%$.

The portable infrared thermometer and thermal infrared imager were calibrated with a standard calibration blackbody (BDB15, with a temperature precision of $\pm 0.1^{\circ} \mathrm{C}$ and a resolution of $0.1^{\circ} \mathrm{C}$ ) prior to the observations in order to eliminate the systematic error generated by the use of different instruments (Wang et al. 2011). To observe LST, the portable infrared thermometer MAX4 $4^{\mathrm{TM}}$ was placed far away from the observers. This device was placed at a height of $0.5 \mathrm{~m}$ above the object surface to measure the surface radiative temperature. We began to record temperatures after the devices became stable for 1-3 s. Continuous observations were made at all sites in the morning (11:00-11:30 a.m.) and at noon (12:30-13:00 p.m.). Ten observations were collected at each site during the study period, and the average values were calculated as the final temperature for this object. The thermal infrared imager FLIR T425 was installed $100 \mathrm{~m}$ above the ground. At this height, it can effectively observe the spatial characteristics of surrounding land surfaces. To preserve the measurement precision, the tilting angle of the imagers was less than $40^{\circ}$ and the maximum FOV distance was $2 \mathrm{~km}$. Prior to measurement, the thermal infrared imager was calibrated using the LST measured by the portable 
infrared thermometers for the same objects. During the measurement, the daily mean air temperature was $18-24{ }^{\circ} \mathrm{C}$, with $3{ }^{\circ} \mathrm{C}$ higher at noon than that in the morning. The air humidity was close to the long-term mean $(30 \%)$ for Beijing, and the wind speed was lower than $2 \mathrm{~m} / \mathrm{s}$.

We selected four representative land-use/landcover types to implement the LST measurement experiments for urban-rural landscape components including urban impervious surface, urban green space, cropland, and water body (Fig. 1). The first selected zone (Z1) represented the urban impervious surface and green space in the city. On the roof of a 100-m tall building in the Breezy Woods Oasis residential area in Chaoyang District of Beijing, we installed a thermal infrared imager and a highresolution camera to acquire infrared images for the surrounding buildings, the impervious surface area of a plaza, and green space in Olympic Park. Meanwhile, we also used the portable infrared thermometer to measure temperature at the ground surfaces of buildings, plaza, green space, and water bodies around this

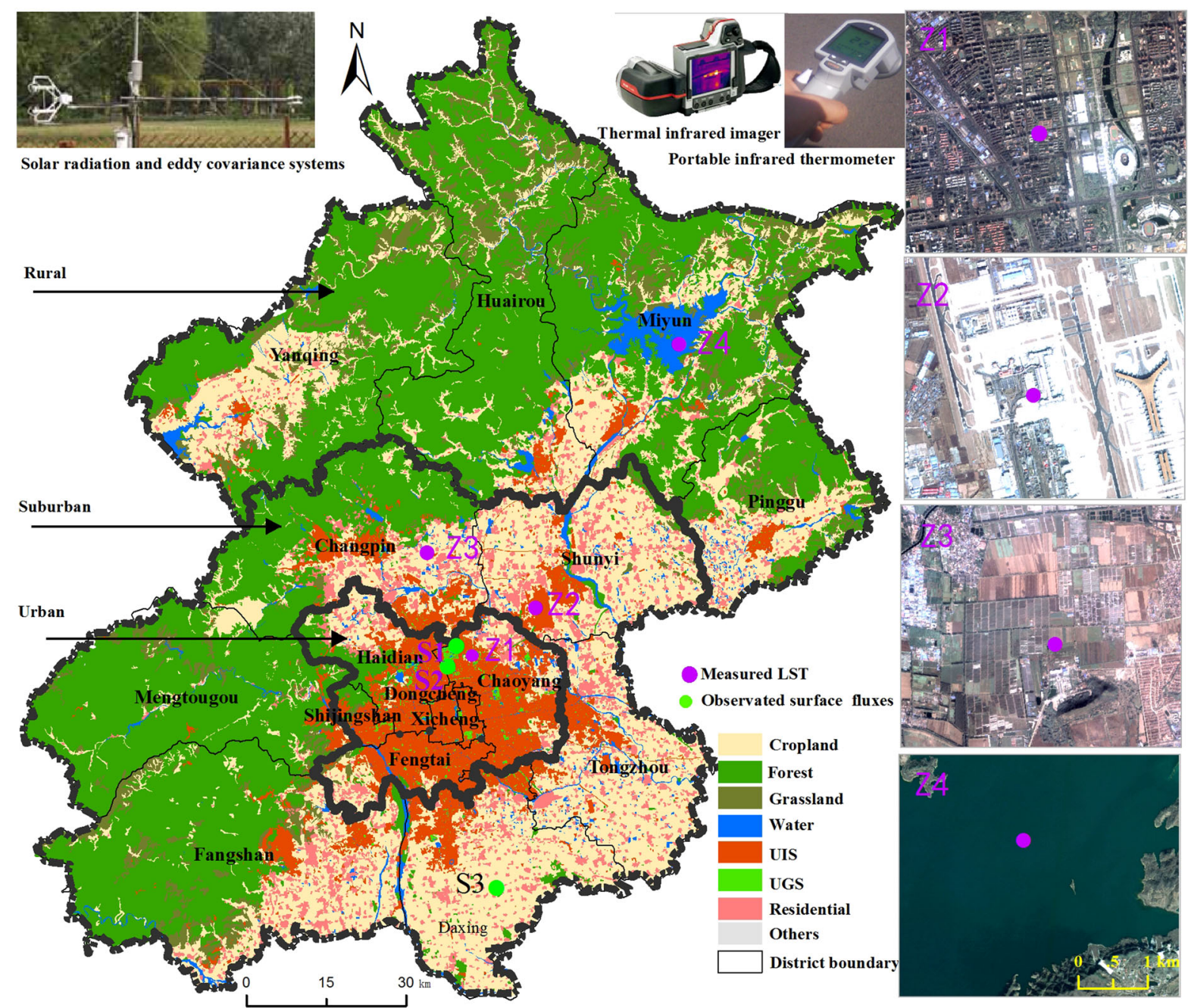

Fig. 1 The study area and the selected observation sites for ground-based observations of land surface temperature (LST) as well as radiation and energy fluxes. Z1, LST observation site for urban impervious surface (UIS) and urban green space (UGS); Z2, LST observation site for concrete surface; Z3, LST observation site for cropland; Z4, LST observation site for water body. $S 1$ radiation and energy flux observation site for UIS; $S 2$ radiation and energy flux observation site for UGS; $S 3$ radiation and energy flux observation site for cropland. The aerial photos at the right column showed the landscape structure in the LST observation sites (Z1, Z2, Z3 and $\mathrm{Z} 4$, respectively) 
observation site. The second zone (Z2), which is located at the Beijing International Airport, was selected to represent a concrete land surface. Portable infrared thermometers were used to measure surface temperature of the airport tarmac. We selected the third zone (Z3) to represent cropland located in Xiaotangshan and the fourth zone (Z4) to represent the Miyun Reservoir water body.

Ground-based measurements of surface radiation and heat fluxes

We also observed surface radiation and heat flux components for urban impervious surface, urban green space, and cropland. We established stations S1 and $\mathrm{S} 2$ to observe radiation components and heat fluxes at urban impervious surface and urban green space, respectively, which are located at the same zone (Z1) for LST observation (Fig. 1). The observation instruments at S1 and S2 were installed at 2.5 and $1.6 \mathrm{~m}$ above the ground, respectively. Within the $1-\mathrm{km}$ buffer zones of the two observation sites, the major land-cover types are impervious surface and vegetation. The urban impervious surface area at the station S1 accounts for $71 \%$ of the buffer zone, and the vegetated area at station S2 accounts for $78 \%$ of the buffer zone. In addition, we also collected the flux data at station S3 for cropland in Daxing District (Fig. 1) (Liu et al. 2013). The observation instrument was installed at $3.0 \mathrm{~m}$ above the ground. The instruments for measuring radiation and surface heat fluxes include a three-dimensional ultrasonic anemometer (CSAT3), a humidity and temperature sensor (HMP155), a 4-component net radiation sensor (HFP01), and a soil heat flux sensor. The observation variables include upwelling and downwelling short-wave/long-wave radiation, albedo, land surface net radiation, sensible heat flux, latent heat flux, soil heat flux, and radiation temperature. For analysis, we first selected all the observation data during daytime (i.e., the hours with net radiation flux $>0$ ) and removed the hard spikes and soft spikes. The data were further corrected using time-lagging, ultrasonic virtual temperature and air density (WPL correction) methods (Webb et al. 1980). Finally, the sensible and latent fluxes were corrected using the Bowen ratio energy balance closure method (Twine et al. 2000). We obtained the land surface radiation and energy fluxes for impervious surface, urban green space, and cropland during the time when the MODIS satellite passed over the observation sites between 11:00 and 11:30 a.m..

MODIS-based observations and parameterization

On September 20th, 2011, the Terra MODIS satellite passed the observation sites at 11:10 a.m. local civil time (LCT) with a solar angle of $40.37^{\circ}-41.84^{\circ}$. Two datasets from MODIS products were used to retrieve LST: (1) the 250-m spatial resolution MODIS 1B products and the $1-\mathrm{km}$ resolution brightness data from the thermal infrared bands $31(10.78-11.28 \mu \mathrm{m})$ and $32(11.77-12.27 \mu \mathrm{m})$. The brightness can be calculated as:

$T_{i}=\frac{C_{2}}{\lambda \ln \left(1+C_{1} / \lambda_{i}^{5} R_{i}\right)}$,

where $T_{i}$ is the brightness of bands 31 and 32, $i$ is the band number (31 or 32 ), $R_{i}$ is the radiance at the top atmosphere of band $i, \lambda$ is the effective wavelength, $C_{1}$ and $C_{2}$ are constants $C_{1}=1.19104 \times 10^{8} \mathrm{~W}$ $\mu \mathrm{m}^{4} / \mathrm{m}^{2} /$ srand $\quad C_{2}=1.43887 \times 10^{4} \mu \mathrm{m} \mathrm{K} \quad$ (Zhou et al. 2009).

The parameters (e.g., $C_{1}$ and $C_{2}$ ) are derived from either empirical knowledge or regression analysis in terms of the natural land surfaces. Split-window algorithms were first introduced by Becker and $\mathrm{Li}$ (1995), and then Mao et al. (2005) and Wan et al. (2002) further developed two generalized split-window algorithms for LST retrieval based on MODIS data. Subsequent studies indicated that the Mao et al. (2005) retrieval algorithm was better than other algorithms for retrieving LST based on MODIS data (Zhou et al. 2009); therefore, we applied the Mao et al. (2005) algorithm to retrieve LST in this study. We calculated the specific emissivity based on the $30 \mathrm{~m} \times 30 \mathrm{~m}$ Landsat TM land-use/land-cover information and $1-\mathrm{km}$ resolution data for the fractions of impervious surface area and green space (Liu et al. 2010; Kuang 2012a; Kuang et al. 2013, 2014).

The Mao et al. (2005) retrieval algorithm after calibration is listed as follows:

$$
\begin{aligned}
T_{S}= & \alpha\left(C_{32}\left(B_{31}+D_{31}\right)-C_{31}\left(D_{32}+B_{32}\right)\right) / \\
& \left(C_{32} A_{31}-C_{31} A_{32}\right)+\beta
\end{aligned}
$$

where $T_{S}$ is the LST and $\alpha$ and $\beta$ are the fitted regression parameters for surface temperature 
between the sampled ground-based and remote-sensing observations of four zones in Fig. 1, which were set as 0.7554 and 7.5146. The coefficient of $A_{31}, A_{32}$, $B_{31}, B_{32}, C_{31}, C_{32}, D_{31}$, and $D_{32}$ are the intermediate parameters determined by the atmospheric transmittance and surface emissivity from the following formula.

$$
\begin{aligned}
A_{31}= & 0.13834 \times \varepsilon_{31} \times \tau_{31}, \\
B_{31}= & 0.13834 \times T_{31}+31.80148 \times \varepsilon_{31} \times \tau_{31} \\
& -31.80148, \\
C_{31}= & \left(1-\tau_{31}\right) \times\left(1+\left(1-\varepsilon_{31}\right) \times \tau_{31}\right) \\
& \times 0.13834, \\
D_{31}= & \left(1-\tau_{31}\right) \times\left(1+\left(1-\varepsilon_{31}\right) \times \tau_{31}\right) \\
& \times 31.80148, \\
A_{32}= & 0.11952 \times \varepsilon_{32} \times \tau_{32}, \\
B_{32}= & 0.11952 \times T_{32}+26.80148 \times \varepsilon_{32} \times \tau_{32} \\
& -26.80148, \\
C_{32}= & \left(1-\tau_{32}\right) \times\left(1+\left(1-\varepsilon_{32}\right) \times \tau_{32}\right) \\
& \times 0.11952, \\
D_{32}= & \left(1-\tau_{32}\right) \times\left(1+\left(1-\varepsilon_{32}\right) \times \tau_{32}\right) \\
& \times 26.80148,
\end{aligned}
$$

where $\varepsilon_{31}, \varepsilon_{32}$ are the surface emissivity of bands 31 and $32 ; \tau_{31}, \tau_{32}$ are the atmospheric transmittance of bands 31 and 32; $T_{31}, T_{32}$ are the brightness temperature (also see Eq. 1) (Mao et al. 2005).

We used the mean LST measured from groundbased observations during $10 \mathrm{~min}$ between 11:00 and 11:20 a.m. LCT when the MODIS satellite passed over the observation sites to recalibrate the $\alpha$ and $\beta$ parameters in Eq. (2) for different land surfaces (both mixed and pure pixels). In the urban area, most of the land surfaces are impervious, green space, and water. By multiplying the LST with the fractions of each surface type within a MODIS pixel (i.e., $1 \mathrm{~km} \times 1 \mathrm{~km}$ ), we calculated the mean LST of this mixed pixel. The LST for each land-cover type in a pixel were derived from the thermal infrared imagers and portable infrared thermometers. We obtained 15 samples (or MODIS pixels) for calibration of the parameters for the Mao et al. (2005) algorithm. Finally, the parameters $\alpha$ and $\beta$ in Eq. (2) were determined as 0.7554 and 7.5146 , respectively. The spatial patterns among the improved Mao algorithm (Fig. 2a), MODIS products (http://www.modis.gsfc. nasa.gov/data/dataprod/dataproducts.php?MOD_ NUMBER=11, Fig. 2b) and Mao algorithm (Fig. 2c) were compared and their accuracy were evaluated. Based on the calibrated parameters, the mean standard error was less than $2{ }^{\circ} \mathrm{C}$ and the root-mean-square error was $1.42{ }^{\circ} \mathrm{C}$ between the improved Mao et al. (2005) retrieval algorithm and observed LST.

Auxiliary data

Several auxiliary datasets were used to identify the causes of LST differences for various land surfaces at regional scale, including 2010 Landsat TM/ETM+ land-cover/land-use data (30-m spatial resolution) (Liu et al. 2010; Kuang 2012b; Kuang et al. 2013, 2014), 2010 aerial photos of Beijing (spatial resolution $0.5 \mathrm{~m}$ ), SRTM elevation data (spatial resolution $90 \mathrm{~m}$ ), and MODIS NDVI data (spatial resolution $1 \mathrm{~km}$ ).

Data analysis methods

The analysis of the LST along an urban-rural gradient was organized at four levels (Fig. 3): observation objects (i.e., urban land, rural land), land-cover types, land-use types, and urban structures and materials ( $\mathrm{Wu}$ and David 2002). The analysis of LST for various land surfaces was based on both ground-based observations and MODIS retrieval, whereas the regional LST was based on the MODIS retrieval LST derived from the calibrated Mao et al. (2005) algorithm.

The LST difference among various land surfaces is calculated as:

$\Delta T_{i, j, n}=\frac{T_{i, n} \varepsilon_{i, n}}{0.95}-\frac{T_{j, n} \varepsilon_{j, n}}{0.95}$,

where $\Delta T_{i, j}$ is the LST difference between $i$ and $j$ land surfaces, $T_{i}$ and $T_{j}$ are LSTs of $i$ and $j$ land surfaces, respectively, $n$ is the observation time period, and $\varepsilon_{i}$ and $\varepsilon_{j}$ are the specific emissivity for $i$ and $j$ land surfaces at the wavelength between 8 and $14 \mu \mathrm{m}$. For various observation periods and land surfaces, the specific emissivity is different (Table 1).

The statistical analyses were conducted using SPSS 16.0. We used one-way analysis of variance (ANOVA) to test the statistical significance of LST 


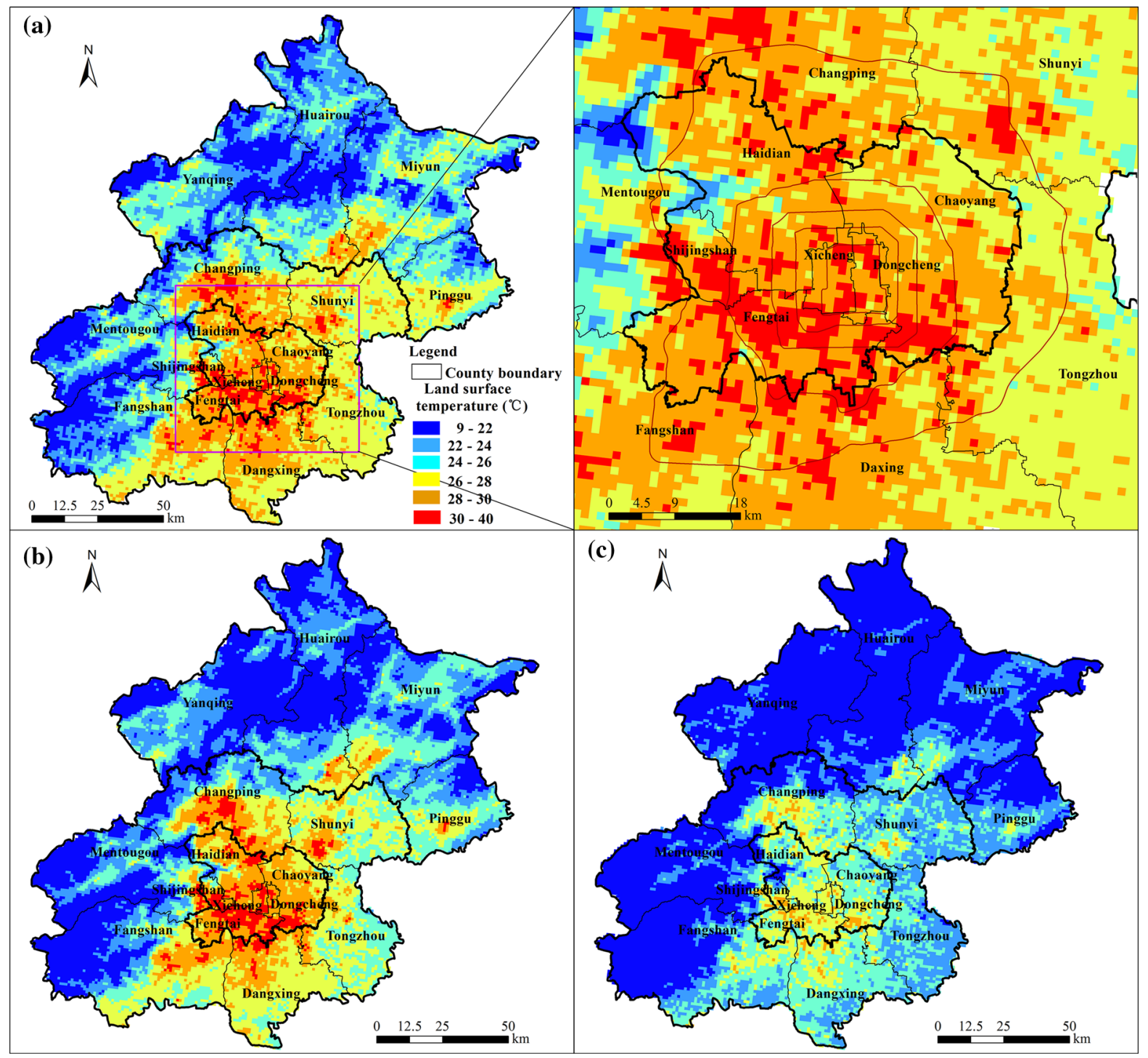

Fig. 2 Spatial distribution of land surface temperature (LST) as retrieved from Mao et al. (2005) algorithm and MODIS products. a Improved Mao's algorithm; b MODIS products; c Mao's algorithm

among different land uses, land covers, and building materials. We considered statistical significance at a confidence level of $95 \%(p=0.05)$ unless specifically stated. LST is not only influenced by land-use/ land-cover types, but also by elevation, vegetation coverage, local meteorological conditions, and landscape composition. Therefore, even for the same landuse type, the mean LST may be different in different locations along the urban-rural gradient. In this study, the simple linear regression was conducted to evaluate the relationships between LST and elevation (derived from digital elevation model, DEM) and polynomial regression $\left(\mathrm{Y}=\mathrm{aX}^{3}+\mathrm{bX}^{2}+\mathrm{cX}+\delta\right)$ was conducted to explore the relationship between LST and vegetation fraction (which is represented by the Normalized Difference Vegetation Index, NDVI).

\section{Results and analysis}

Observed LST of various urban land surfaces

Using portable infrared thermometers and thermal infrared imagers to obtain ground-based observation 
Fig. 3 The illustrations of four levels of analyses for comparing land surface temperatures of various land-cover types, land-use types, building materials and landscape components along the urban-rural gradient

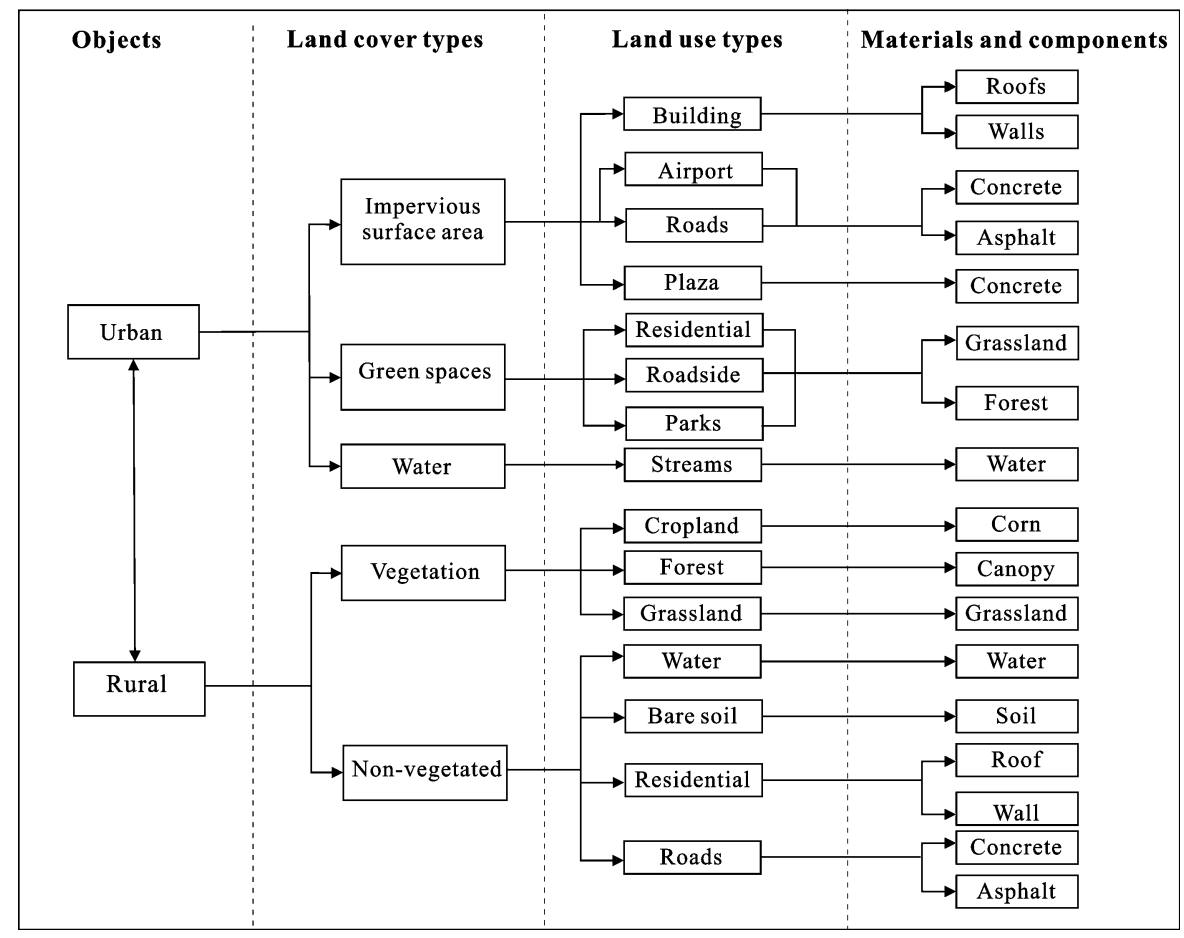

Table 1 Specific emissivity $\left(\varepsilon_{i}\right)$ of different land surfaces used in this study

\begin{tabular}{lll}
\hline Land surfaces & $\begin{array}{l}\text { Specific } \\
\text { emissivity }\end{array}$ & Reference(s) \\
\hline Cropland & 0.982 & Qin et al. (2004) \\
Forest & 0.988 & Qin et al. (2004) \\
Shrubland & 0.986 & Humes et al. (1994), \\
& & Liu et al. (2011) \\
Grassland & 0.982 & Labed and Stoll (1991) \\
Water body & 0.995 & Zheng et al. (2010) \\
Bare soil & 0.972 & Qin et al. (2004) \\
Building & 0.970 & Qin et al. (2004) \\
Green space & 0.985 & Humes et al. (1994) \\
Asphalt and concrete & 0.968 & Wang et al. (2011) \\
\hline
\end{tabular}

points ( $\mathrm{n}=2250$ ), we compared the LSTs for different land-use/land-cover types. In the morning (11:00-11:30 a.m. LCT), the highest value of mean LST was found on the building roof $\left(36.80{ }^{\circ} \mathrm{C}\right)$, followed by the airport tarmac $\left(30.65^{\circ} \mathrm{C}\right)$, paved roads $\left(30.03{ }^{\circ} \mathrm{C}\right)$, plaza $\left(28.30^{\circ} \mathrm{C}\right)$, and green space $\left(24.14^{\circ} \mathrm{C}\right)$. The lowest value of mean LST was recorded for the water body $\left(11.87^{\circ} \mathrm{C}\right.$, Fig. 4). The mean LSTs for various green-space types were ranked as roadside green space $\left(25.32{ }^{\circ} \mathrm{C}\right)>$ residential green space $\left(24.76^{\circ} \mathrm{C}\right)>$ park green space $\left(22.34^{\circ} \mathrm{C}\right)$. Buildings, plaza, and paved roads showed strong "hot fields," while the green spaces acted as obvious "cold fields." At noon (12:30-13:00 LCT), the mean LSTs of impervious surface areas (including building roof, airport tarmac, paved roads, and plaza) ranged $30-39^{\circ} \mathrm{C}$, while green spaces ranged $24-27^{\circ} \mathrm{C}$. The maximum LST difference was $24.93{ }^{\circ} \mathrm{C}$ between the building roof and water body. In addition, we also found large variations among the measurements for a specific land-use type. The variations among measurements for three green-space types ranged $6-14{ }^{\circ} \mathrm{C}$, with lower variations in the park green space. The smallest variation (about $4{ }^{\circ} \mathrm{C}$ ) occurred at the water body due to its high thermal inertia and thermal capacity, and relatively low thermal conductivity. We found large spatial heterogeneities of radiative temperatures based on the measurements from thermal infrared imagers (Fig. 5). In the urban area, green spaces had significantly lower $(p<0.01)$ radiative temperatures in contrast to the roads and the roofs of buildings, and the roofs were the hottest surface in the morning. The radiative temperatures were significantly different $(p<0.05)$ for the same types of buildings with various 
Fig. 4 Mean, maximum, and minimum land surface temperatures for different land surfaces in two time periods (i.e., morning: 11:00-11:30 a.m. LCT; noon: 12:30-1:00 p.m. LCT)

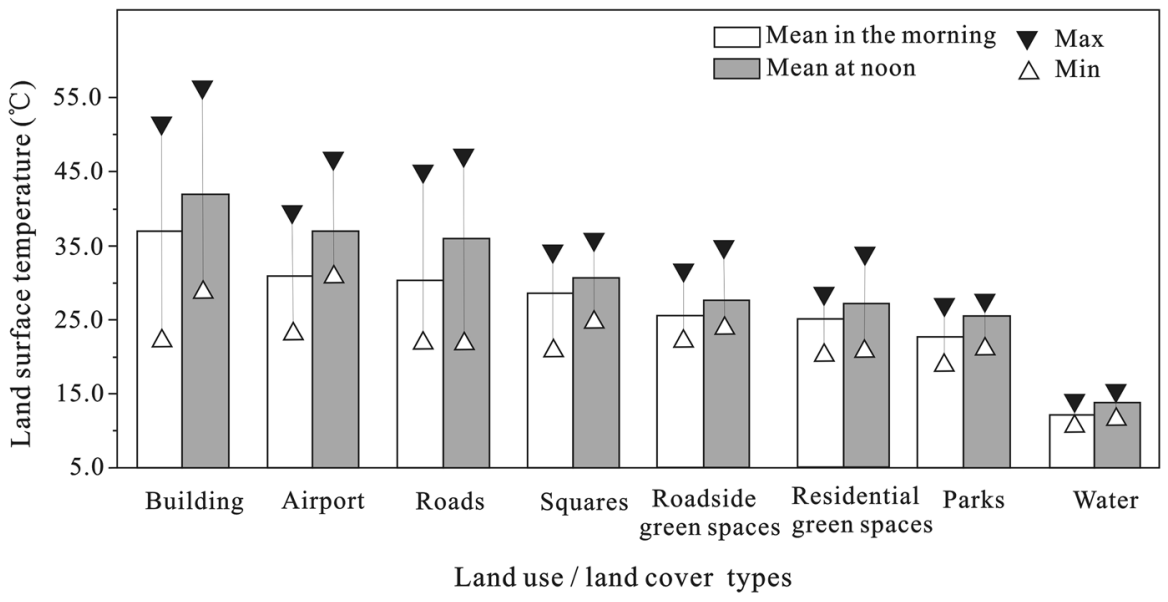

observations using the portable infrared thermometer and thermal infrared imager (Fig. 4).

Overall, our results indicated that urban area LSTs were about $3-6{ }^{\circ} \mathrm{C}$ higher than those of rural areas. The LST generally descended with increasing distance from the urban center. The districts closer to the urban areas, such as Dongcheng, Xicheng, Haidian, Chaoyang, Shijingshan, and Fengtai districts, generally had $(p<0.05)$ higher LSTs than those in the suburban areas, such as Daxing, Tongzhou, Fangshan, Mentougou, Changping and Shunyi districts. The rural areas, such as Huairou District, Pinggu District, Yanqing County, and Miyun County, had even lower LSTs. For grassland and forest, the LSTs in the urban areas were about $3{ }^{\circ} \mathrm{C}$ and $2{ }^{\circ} \mathrm{C}$ respectively, higher than those in the suburban areas, and the difference between suburban areas and rural areas was smaller $(p<0.01)$. For water bodies, the urban LSTs were about $3{ }^{\circ} \mathrm{C}$ and $6{ }^{\circ} \mathrm{C}$ higher than those in the suburban and rural areas, respectively.

Land surface radiation and energy fluxes of different land-use types

Atmospheric conditions, radiation and energy fluxes, in addition to land surface physical properties, play a major role in the difference in LSTs for various land surfaces. Therefore, we specifically observed the net radiation, downwelling/upwelling shortwave and longwave radiation, and the energy fluxes during 11:00-11:30 a.m. LCT and daytime (i.e., the hours with downwelling short-wave radiation $>0 \mathrm{~W} / \mathrm{m}^{2}$ ) on September 20th, 2011, at the selected sites S1, S2, 
Fig. 5 The locations for observing land surface temperatures of various urban structures and landscape components (i.e., buildings, plaza, and park) in the Maple Oasis residential area $(\mathrm{Z} 1$ in Fig. 1) and the corresponding infrared images obtained from thermal infrared imagers. a The observation range of the thermal infrared imagers (yellow boxes) and observation position (yellow circle); b1-b3 landscape pictures of buildings, plaza, and green space, respectively. c1-c9 The images obtained from thermal infrared imagers; $\mathrm{c} 1, \mathrm{c} 2$, and $\mathrm{c} 3$ are the thermal infrared images of b1, b2, and b3, respectively; c4-c6 represent impervious surfaces of buildings and plaza; c7-c9 represent the green space

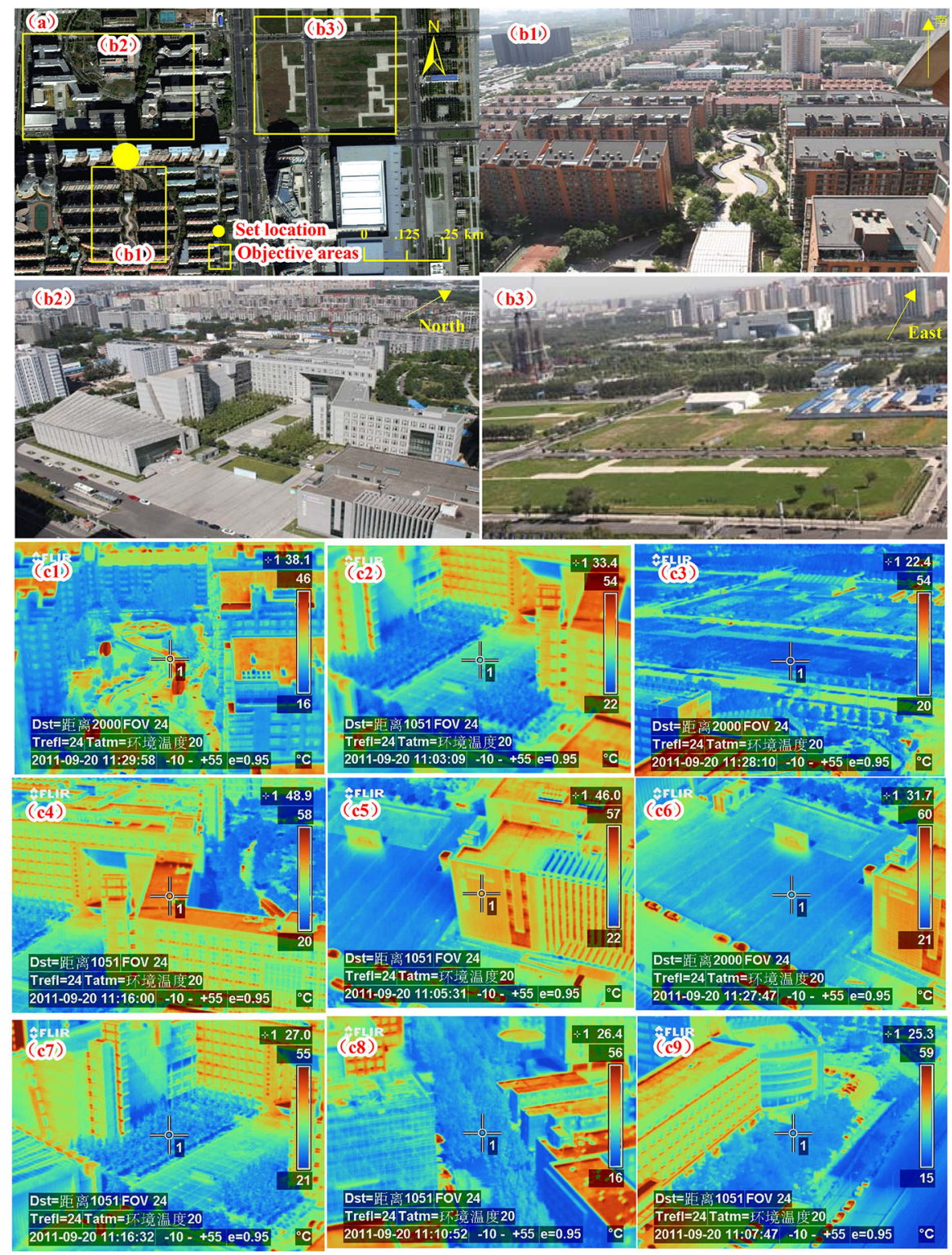

and S3 (Tables 3, 4). The downwelling short-wave radiation was higher than $700 \mathrm{~W} / \mathrm{m}^{2}$ for all three observation sites during 11:00-11:30 a.m. LCT (Table 3). The upwelling long-wave radiation was higher than $400 \mathrm{~W} / \mathrm{m}^{2}$ during 11:00-11:30 a.m. LCT, which was comparable with the daytime observations. Cropland had the highest net surface radiation on average, and the impervious surface had the lowest at $396.07 \mathrm{~W} / \mathrm{m}^{2}$.

The land surface reflectance of different land-use types were ranked as impervious surface area $>$ urban green space $\approx$ rural cropland (Table 4 ). The impervious surface area had significantly $(p<0.001)$ higher reflectance and lower net radiation than urban green space and rural cropland, while no significant difference $(p<0.05)$ between urban green space and rural cropland. The ratio of sensible heat to net radiation $(\mathrm{H} /$ $R_{n}$ ) was about 0.63 and the ratio of latent heat to net radiation ( $L E / R_{n}$ ratio) was 0.19 for urban impervious surface. The radiation energy at the impervious surface was primarily composed of sensible heat, with a Bowen ratio (H/LE) of 4.03. For urban green space, 
latent heat fraction (0.58) was higher than sensible heat $(0.32)$ because of vegetation transpiration. For rural cropland, the lowest reflectance $(0.14)$ resulted in the highest net radiation. Similar to green space, the high plant transpiration in cropland caused higher latent heat fraction (0.63) than sensible heat fraction

Table 2 Summary statistics for LSTs for different land use types along an urban-rural gradient

\begin{tabular}{lllll}
\hline Land use types & $\begin{array}{l}\text { Max } \\
\left({ }^{\circ} \mathrm{C}\right)\end{array}$ & $\begin{array}{l}\text { Min } \\
\left({ }^{\circ} \mathrm{C}\right)\end{array}$ & $\begin{array}{l}\text { Mean } \\
\left({ }^{\circ} \mathrm{C}\right)\end{array}$ & SD \\
\hline $\begin{array}{l}\text { Built-up area } \\
\text { Rural residential }\end{array}$ & 35.92 & 20.34 & 27.99 & 2.64 \\
$\quad 34.51$ & 18.47 & 26.59 & 2.55 \\
$\quad$ area & & & & \\
Cropland & 34.13 & 18.32 & 25.32 & 2.56 \\
Forest & 30.62 & 11.47 & 23.18 & 3.09 \\
Grassland & 34.19 & 12.81 & 24.81 & 2.94 \\
Water body & 23.63 & 10.97 & 21.24 & 3.67 \\
\hline
\end{tabular}

(0.30). The impervious surface had a significantly higher $H / R_{n}$ ratio as compared to urban green space and rural cropland, while $L E / R_{n}$ showed an opposite pattern. The sensible heat flux dominated energy balance at the impervious surface, resulting in significantly ( $p<0.001)$ higher LST; latent heat flux played the major role in the energy balance of green space and cropland, resulting in lower LST as compared to impervious surface. From these analyses, we concluded that the difference in LST between impervious surface and vegetated surface (i.e., urban green space and rural cropland) might be primarily determined by the significantly different energy balance pattern.

The effects of topography and vegetation coverage on LST

We overlaid the retrieved MODIS LST with elevation and vegetation cover (represented by NDVI) to find

Table 3 Different components of solar radiation $\left(\mathrm{W} / \mathrm{m}^{2}\right)$ during the observation periods (i.e., 11:00-11:30 a.m. and daytime) on September 20th, 2011

\begin{tabular}{lllllll}
\hline Site (land surface) & Time & $\begin{array}{l}\text { Downwelling } \\
\text { short-wave } \\
\text { radiation }\end{array}$ & $\begin{array}{l}\text { Upwelling } \\
\text { short-wave } \\
\text { radiation }\end{array}$ & $\begin{array}{l}\text { Downwelling } \\
\text { long-wave } \\
\text { radiation }\end{array}$ & $\begin{array}{l}\text { Upwelling } \\
\text { long-wave } \\
\text { radiation }\end{array}$ & $\begin{array}{l}\text { Net radiation } \\
\text { S1 (UIS) }\end{array}$ \\
\hline 11:00-11:30 a.m. & 759.29 & 219.47 & 310.79 & 454.54 & 396.07 \\
S2 (UGS) & Daytime & 409.55 & 119.29 & 303.96 & 443.96 & 262.47 \\
& 11:00-11:30 a.m. & 777.37 & 142.85 & 330.42 & 472.02 & 492.92 \\
S3 (Cropland) & Daytime & 451.85 & 83.12 & 325.79 & 428.73 & 351.87 \\
& 11:00-11:30 a.m. & 753.40 & 99.87 & 313.64 & 444.36 & 522.80 \\
& Daytime & 545.43 & 82.46 & 310.41 & 432.58 & 342.05 \\
\hline
\end{tabular}

UIS urban impervious surface; UGS urban green space

Denotes the hours with downwelling short-wave radiation $>0 \mathrm{~W} / \mathrm{m}^{2}$

Table 4 Land surface reflectance, net solar radiation $\left(\mathrm{W} / \mathrm{m}^{2}\right)$, Bowen ratio, and the ratios of different heat flux components to net radiation during the observations at selected sites on September 20th, 2011

\begin{tabular}{llllllll}
\hline Site (land surface) & Time & Reflectance & Rn $\left(\mathrm{W} / \mathrm{m}^{2}\right)$ & LE/Rn & H/Rn & G/Rn & Bowen Ratio (H/LE) \\
\hline S1 (UIS) & $11: 00-11: 30$ a.m. & 0.29 & 396.07 & 0.17 & 0.63 & 0.20 & 3.64 \\
& Daytime & 0.30 & 262.47 & 0.19 & 0.63 & 0.18 & 4.03 \\
S2 (UGS) & 11:00-11:30 a.m. & 0.18 & 492.92 & 0.55 & 0.40 & 0.05 & 0.74 \\
& Daytime & 0.18 & 351.87 & 0.58 & 0.32 & 0.10 & 0.57 \\
S3 (Cropland) & 11:00-11:30 a.m. & 0.13 & 522.80 & 0.59 & 0.35 & 0.06 & 0.60 \\
& Daytime & 0.14 & 342.05 & 0.63 & 0.30 & 0.07 & 0.46
\end{tabular}

UIS urban impervious surface; $U G S$ urban green space; $R n$ net radiation; $L E$ latent heat flux; $H$ sensible heat flux; $G$ ground heat flux 
the relationships between LST and elevation and vegetation cover (Fig. 6). A simple linear regression between LST and elevation indicated that LST decreased significantly with increasing elevation (Fig. $6 ; R^{2}=0.80 ; p<0.01$ ). Beijing is located in the North China Plain, with a mountainous terrain (between $1,000 \mathrm{~m}$ and $1,500 \mathrm{~m}$ elevation) in the northwest and a flat plain (between 0 and $100 \mathrm{~m}$ elevation) in the southeast. The mean LST in the northwestern Beijing (higher elevation) was $19.65{ }^{\circ} \mathrm{C}$, ranging between $14.14{ }^{\circ} \mathrm{C}$ and $24.08{ }^{\circ} \mathrm{C}$, while the mean LST in the southeast was $28.15^{\circ} \mathrm{C}$, ranging between $23.87{ }^{\circ} \mathrm{C}$ and $32.82{ }^{\circ} \mathrm{C}$. The polynomial regression analysis between LST and NDVI indicated that LST first increased with NDVI when NDVI $\leq 0.2$, then slightly decreased with NDVI when $0.2<\mathrm{NDVI}<0.4$, and greatly decreased when NDVI $\geq 0.4$ (Fig. 6). This pattern reflected an urbanrural gradient of NDVI: low NDVI values in the inner city (mostly built-up land), relatively high NDVI in the suburban area (mostly residential and cropland

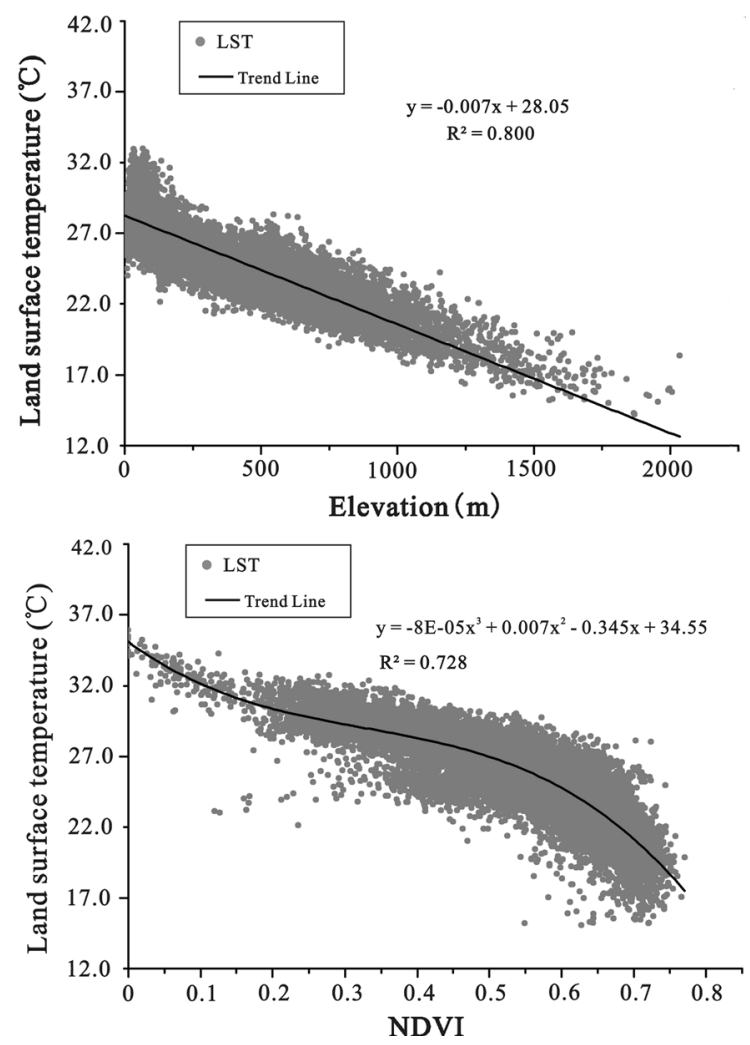

Fig. 6 The relationships between land surface temperatures and elevation (top) and normalized difference vegetation index (NDVI) area), and the highest NDVI in the rural area (mostly forest).

Effects of landscape components and building materials on LST

Within the urban area, LSTs are closely related to the landscape components on the combination of multiple land-use/land-cover types and building materials. The urban land surface primarily consists of three major land-cover types: impervious surface, green space, and water. Based on the three observation approaches of direct measurements, thermal infrared imagers, and portable infrared thermometers, we found that the LSTs among these three land-cover types were significantly different, with a mean LST $6-12{ }^{\circ} \mathrm{C}$ higher at the impervious surface than at the green space. Therefore, the fractions of each land-cover component might finally determine the overall LST. In addition, we found that building materials, shapes, colors, and shadows significantly influenced the infrared images and thus LST. For example, the LST of a dark-gray roof was about $4.8{ }^{\circ} \mathrm{C}$ higher than that of a white-gray roof due to the higher energy absorption capacity of dark-gray materials. The LST of a concrete plaza in the shadow of tall buildings was about $10{ }^{\circ} \mathrm{C}$ lower than that of a concrete plaza without shadow. LST of an asphalt road was about $2{ }^{\circ} \mathrm{C}$ higher than that of a concrete road because the lighter color of the concrete has a higher reflectance and lower absorption to solar radiation. The building roof was directly exposed to solar radiation, so its LST was significantly higher than that of the lateral building walls. Therefore, the building materials with higher heat adsorption capacity should contribute more to the formation of UHIs. The different impacts of building materials were primarily reflected in their differences in thermal conductivity, reflectance, and thermal inertia. The buildings, roads, and plazas are generally made of bricks, tiles, concrete, and asphalt. Although these materials have high reflectance to solar radiation, they also have faster heat transfer and higher heat-trapping capacity. These characteristics lead to built-up land in the urban areas having the highest LSTs as compared to other land-cover types or locations along the urban-rural gradient. The green space with grass and trees has high vegetation evapotranspiration. Therefore, the thermal inertia and the resistance to rising surface temperature were very large, resulting in significantly lower LST than the impervious surface. 


\section{Discussion}

\section{Effects of urbanization on LST in Beijing}

Urbanization, the process of converting natural vegetation or cropland to urban built-up land, is a major driver of land-use/land-cover change. The change in LST, an important parameter in studying UHI, is primarily related to the altered landscape structure due to rapid urbanization. For instance, urban areas covered with impervious surfaces such as buildings, asphalt, concrete, etc. generally have higher absorption of solar radiation and larger thermal conductivity and capacity, which may result in a relatively higher LST as compared to the surrounding areas. In this study, we found a significant descending trend in LST along the urban-rural gradient in terms of the distance from the city center. The land-cover types (such as vegetation or impervious materials) and spatial composition in the landscapes are also important in determining both internal and external urban LSTs (Rosenzweig et al. 2005; Zhou et al. 2011a, b). Furthermore, the spatial heterogeneity of landscapes may represent the largest intra-urban and rural differences in LST (Buyantuyev and Wu 2010). Using the ground-based observations and the MODIS remotelysensed products, we found that the LSTs of various land surfaces followed an order of urban impervious surface $>$ residential area $>$ cropland $>$ natural vegetation $>$ water body. This implies that the higher fractions of urban impervious surface could result in higher LST in the urban area. Large magnitude of urban impervious surface is the dominant driver in the creation of a urban heat island. Beijing has experienced fast urban expansion in the past three decades, with more than a threefold increase in built-up area since 1984 (Kuang 2012b), which resulted in an increase of UHI by $0.31{ }^{\circ} \mathrm{C} /$ decade from 1960 to 2000 (Lin and Yu 2005). By the end of 2010, 19.62 million people lived in the city, and the population density was 1,195 persons $/ \mathrm{km}^{2}$. Its total area was $16,801 \mathrm{~km}^{2}$, with $1,582.24 \mathrm{~km}^{2}$ of impervious surface covering $72.6 \%$ of the built-up area (Kuang 2011, 2012a; Kuang et al. 2013). Yu et al. (2005) indicated that the increasing urban impervious surface area in Beijing resulted in an increase of LST by $9.18{ }^{\circ} \mathrm{C}$, although the increasing air temperature also partly contributed to increased temperatures. Our analysis for the relationship between NDVI and LST showed that LST significantly decreased with increasing NDVI (Fig. 6). Increases of urban green space fraction in the urban area could reduce the increasing trend of LST (Weng et al. 2004; Buyantuyev and Wu 2010; Li et al. 2012). We found that the urban landscape cover components (e.g., impervious surface or green space) are the most important key factors related to LST. Therefore, the policy makers and city designers of Beijing should consider increasing the proportion of green space in urban and suburban areas to mitigate the UHI.

\section{LST and land surface energy fluxes}

LST plays a key role in controlling the land surface energy budget (Weng et al. 2013). In turn, the surface energy balance is an essential element of the climate system, and the land surface energy budget can be used to explain the changes of LST. Vegetated surfaces (e.g., green space and cropland) have a high evapotranspiration potential and can release a relatively large amount of absorbed energy as latent heat, resulting in a lower LST. In addition, vegetated surfaces have low thermal conductivity than impervious surfaces and tend to release slowly energy to the air, resulting in relatively low LSTs (Hafner and Kidder 1999; Hawkins et al. 2004). In contrast, urban impervious surfaces have higher thermal conductivity and capacity, and thus tend to absorb more incident solar energy and release their absorbed energy as sensible heat to the air, especially during night time, resulting in higher surrounding temperature. So the green space in an urban area is generally an "urban heat sink" (Carnahan and Larson 1990), whereas the impervious surfaces are "urban heat sources". In this study, we found that the proportion of the components of net radiation (i.e., latent heat, sensible heat, and ground heat fluxes) between urban impervious surface, urban green space and cropland were significantly different. These differences might explain the higher LST in the urban impervious surface areas than in the green space and cropland areas. Based on ASTER remotely-sensed data, Weng et al. (2013) found that net radiation of various land-cover types followed an order of cropland $>$ urban green space $>$ urban impervious surface, which is consistent with our study (Tables 2, 3).

LST and building materials

Besides microclimatic conditions (e.g., air temperature, precipitation, and cloud cover), land use, urban 
structure, and anthropogenic heat sources (Oke 1982), the thermal dynamics in an urban area are also significantly influenced by building materials (Meyn and Oke 2009). The influences of building materials on LST are reflected primarily in differences of the physical properties of materials (e.g., thermal conductivity, reflectance, albedo, and thermal capacity). For example, lighter-colored building materials generally have higher albedo and absorb less heat, while darker materials generally absorb more heat, resulting in higher LST associated with darker-material surfaces. A rough land surface often absorbs more heat as the surface area is larger than smooth land surfaces (Doulos et al. 2004). In addition, the LST of concrete pavements is generally lower than asphalt surfaces (Asaeda et al. 1996). An earlier report indicated that the building materials of old bricks and tiles within the second ring of Beijing had lower reflectance, resulting in an extremely high LST (Liu et al. 2011). Wang et al. (2003) found that the surface roughness of the inner city in Beijing is about an order of magnitude higher than that of the suburban area due to more tall buildings and complex landscape components, which resulted in significant changes in the thermal dynamics (Xu et al. 2009). In this study, we found that LSTs of dark-colored land surfaces and asphalt roads were and higher than white-colored surfaces and concrete roads, respectively. Building roofs had higher LSTs than lateral building walls, and LSTs in the areas of building shadows was lower than those areas without shadows. Therefore, we suggest that the city planners and designers should select building materials with higher albedo and low thermal capacity and rationally arrange land-use components in the urban area.

\section{LST based on different retrieval algorithms}

The measured LST from the portable infrared thermometers and thermal infrared imagers were compared with the retrieved LST based on Mao's algorithm and existing MODIS LST product (Fig. 2). The mean square of LST was $1.48^{\circ} \mathrm{C}$ for improved Mao's algorithm, while it was $1.53{ }^{\circ} \mathrm{C}$ for the MODIS product, indicating a slightly higher accuracy for data retrieved from Mao's algorithm than that for MODIS products (Fig. 2a-c). For pure pixels in the rural areas, the LST from improved Mao's algorithm was generally lower than the observed LST. For cropland, improved Mao's algorithm underestimated the LST, with $0.44{ }^{\circ} \mathrm{C}$ lower than that of the observed value; while MODIS product overestimated the LST, with $1.49{ }^{\circ} \mathrm{C}$ higher than that of the observed value. For forest, the LST from MODIS product was better than that from improved Mao's algorithm, with a difference of 0.73 ${ }^{\circ} \mathrm{C}$ and $2.27{ }^{\circ} \mathrm{C}$ for MODIS product and Mao's algorithm, respectively, as compared to the observed values. For the pure pixels of urban green space, improved Mao's algorithm was better than MODIS products, with a difference of $1.37{ }^{\circ} \mathrm{C}$ and $2.67{ }^{\circ} \mathrm{C}$ respectively from the observed values. For the pure pixels in the urban areas, such as the airport tarmac, improved Mao algorithm was close to the observations, with a small difference of $0.01{ }^{\circ} \mathrm{C}$.

\section{Conclusions}

LST varied significantly along the urban-rural gradient, which is not only determined from the differences in solar radiation but also from the differences in atmospheric environment and land surface characteristics. The integration of ground-based observations with remotely-sensed data proved effective in exploring the spatial and temporal characteristics of LSTs along an urban-rural gradient from the perspectives of land-cover type, land-use types, urban structure, and building materials. The portable infrared thermometer and thermal infrared imagers can observe the LST differences at the local scale for different building materials and provide parameterization and validation data for MODIS retrieval at the medium scale. The improved MODIS retrieval algorithms reduced the mean error to $2{ }^{\circ} \mathrm{C}$ as compared to the observed LST.

The LST was significantly different between urban and rural land surfaces, with LSTs about $3-6{ }^{\circ} \mathrm{C}$ higher in the urban area than in the rural area. Large differences were also found among various intra-urban land-use types (i.e., impervious surface, green space, and water), with LSTs about $6-12{ }^{\circ} \mathrm{C}$ higher at the impervious surface than at the green space. Our results indicate that the different LSTs in the urban area were primarily caused by the differences in land surface radiation and energy fluxes. Sensible heat flux is the major component of net radiation for an impervious surface and thus resulted in increased LST, whereas latent heat flux is the major component of net radiation for green space. 
LST is also significantly influenced by urban structure and building materials in built-up areas, and elevation and vegetation cover in rural area. We found that LSTs decreased with increasing elevation and NDVI. The concrete land surfaces had lower LST than that of asphalt surfaces, and dark-gray buildings had higher LST than white-gray buildings. To alleviate UHI intensity in Beijing, the city planners and designers should pay special attention to selecting appropriate building materials, reasonably arranging urban structures, increasing green space fractions, and designing rational landscape components.

Acknowledgments We thank the National Natural Science Foundation of China (41371408), the National Basic Research Program of China (2014CB954302; 2010CB950900), and National Key Technology R\&D Program (2012BAJ15B02) for financial support. We also thank Dr. Shaomin Liu of Beijing Normal University for providing the radiation and energy fluxes data from the Daxing Station, and Dr. Jianguo Wu for constructive comments/suggestions for this paper.

\section{References}

Alberti M (2009) Advances in urban ecology: integrating humans and ecological processes in urban ecosystems. Springer, New York

Asaeda T, Ca VT, Wake A (1996) Heat storage of pavement and its effects on the lower atmosphere. Atmos Environ 30(3):413-427

Becker F, Li ZL (1995) Surface temperature and emissivity at various scales: definition, measurements and related problems. Remote Sens Rev 12:225-253

Buyantuyev A, Wu JG (2010) Urban heat islands and landscape heterogeneity: linking spatiotemporal variations in surface temperatures to land-cover and socioeconomic patterns. Landscape Ecol 25(1):17-33

Carnahan WH, Larson RC (1990) An analysis of an urban heat sink. Remote Sens Environ 33:65-71

Chen SB, Pan LQ (1997) Effects of urbanization on the annual mean temperature of Beijing. Acta Geogr Sin 52(1):27-36 (in Chinese)

Connors JP, Galletti CS, Chow W (2013) Landscape configuration and urban heat island effects: assessing the relationship between landscape characteristics and land surface temperature in Phoenix, Arizona. Landscape Ecol 28(2):271-283

Dale A, Jeffrey C (1999) Thermal infrared remote sensing for analysis of landscape ecological processes: methods and applications. Landscape Ecol 14:577-598

Doulos L, Santamouris M, Livada I (2004) Passive cooling of outdoor urban spaces: the role of materials. Sol Energy 77(2):231-249

Grimm NB, Faeth SH, Golubiewski NE, Redman CL, Wu JG, Bai XM, Briggs JM (2008) Global change and the ecology of cities. Science 319(5864):756-760
Hafner J, Kidder SQ (1999) Urban heat island effect modeling in conjunction with satellite-derived surface/soil parameters. J Appl Meteorol 38(4):448-465

Hawkins TW, Brazel AJ, Stefanov WL, Bigler W, Saffell EM (2004) The role of rural variability in urban heat island determination for Phoenix, Arizona. J Appl Meteorol 43(3):476-486

Humes KS, Kustas WP, Moran MS, Nichols WD, Weltz MA (1994) Variability of emissivity and surface temperature over a sparsely vegetated surface. Water Resour Res 30(5):1299-1310

Ji CP, Liu WD, Xuan CY (2006) Impact of urban growth on the heat island in Beijing. Chin J Geophys-ch 49(1):69-77 (in Chinese)

Kuang WH (2011) Simulating dynamic urban expansion at regional scale in Beijing-Tianjin-Tangshan metropolitan area. J Geogr Sci 21(2):317-330

Kuang WH (2012a) Evaluating impervious surface growth and its impacts on water environment in Beijing-Tianjin-Tangshan metropolitan area. J Geogr Sci 22(3): 535-547

Kuang WH (2012b) Spatio-temporal patterns of intra-urban land use change in Beijing, China between 1984 and 2008. Chin Geogr Sci 22(2):210-220

Kuang WH, Liu JY, Zhang ZX, Lu DS, Xiang B (2013) Spatiotemporal dynamics of impervious surface areas across China during the early 21 st century. Chin Sci Bull 58(14):1691-1701

Kuang WH, Chi WF, Lu DS, Dou YY (2014) A comparative analysis of megacity expansions in China and the U.S.: patterns, rates and driving forces. Landsc Urban Plan 132:121-135

Labed J, Stoll MP (1991) Spatial variability of land surface emissivity in the thermal infrared band: spectral signature and effective surface temperature. Remote Sens Environ 38(1):1-17

Li JX, Song CH, Cao L, Zhu FG, Meng XL, Wu JG (2011) Impacts of landscape structure on surface urban heat islands: a case study of Shanghai, China. Remote Sens Environ 115:3249-3263

Li XM, Zhou WQ, Ouyang ZY, Xu WH, Zheng H (2012) Spatial pattern of green space affects land surface temperature: evidence from the heavily urbanized Beijing metropolitan area, China. Landscape Ecol 27(6):887-898

Li ZL, Tang BH, Wu H, Ren HZ, Yan GJ, Wan ZM, Trigo IF, Sobrino JA (2013) Satellite-derived land surface temperature: current status and perspectives. Remote Sens Environ 131:14-37

Lin XC, Yu SQ (2005) Interdecadal changes of temperature in the Beijing region and its heat island effect. Chin J Geophys-ch 48:47-54

Liu JY, Zhang ZX, Xu XL, Kuang WH, Zhou WC, Zhang SW, Li RD, Yan CZ, Yu DS, Wu SX, Nan J (2010) Spatial patterns and driving forces of land use change in China during the early 21st century. J Geogr Sci 20:483-494

Liu WY, Gong AD, Zhou J, Zhan WF (2011) Investigation on relationships between urban building materials and land surface temperature through a multi-resource remote sensing approach. Remote Sens Inf 4:46-53

Liu SM, Xu ZW, Zhu ZL, Jia ZZ, Zhu MJ (2013) Measurements of evapotranspiration from eddy-covariance systems and 
large aperture scintillometers in the Hai River Basin, China. J Hydrol 487:24-38

Mao KB, Qin ZH, Shi J, Gong P (2005) A practical split-window algorithm for retrieving land surface temperature from MODIS data. Int J Remote Sens 26(15):3181-3204

Meyn SK, Oke TR (2009) Heat fluxes through roofs and their relevance to estimates of urban heat storage. Energy Buildings 41(7):745-752

Oke TR (1982) The energetic basis of the urban heat island. Q J Roy Meteor Soc 108:1-24

Oke TR (1984) Methods in urban climatology. In: Kirchhofer W, Ohmura A, Wanner H (eds) Applied climatology, Zürcher Geogr. Schriften 14:19-29

Oke TR (1995) The heat island of the urban boundary layer: characteristics, causes and effects. In: Cermak JE, Davenport AG, Plate EJ et al (eds) Wind climate in cities: Proceedings of the NATO Advanced Study Institute, Waldbronn, Germany, July 5-16, 1993. Nato Science Series E, vol 277. Kluwer Academic Publishers, Dordrecht, pp 81-107

Oke TR (2004) Initial guidance to obtain representative meteorological observations at urban sites. Instruments and Observing Methods Report No 81. World Meteorological Organization, Geneva

O’Neill RV, Krummel JR, Gardner RH, Sugihara G, Jackson B, DeAngelis DL, Milne BT, Turner MG, Zygmunt B, Christensen SW, Dale VH, Graham RL (1988) Indices of landscape pattern. Landscape Ecol 1:153-162

Ouyang Z, Xiao RB, Schienke EW, Li WF, Wang X, Miao H, Zheng H (2007) Chapter 27: Beijing urban spatial distribution and resulting impacts on heat islands. In: Hong K, Nakagoshi N, Fu BJ et al (eds) Landscape ecological applications in man-influenced areas: linking man and nature systems. Springer, New York, pp 459-478

Pickett STA, Cadenasso ML, Grove JM, Boone CG, Groffman PM, Irwin E, Kaushal SS, Marshall V, McGrath BP, Nilon CH, Pouyat RV, Szlavecz K, Troy A, Warren P (2011) Urban ecological systems: scientific foundations and a decade of progress. J Environ Manag 92:331-362

Qin ZH, Li WJ, Xu B, Chen ZX, Liu J (2004) The estimation of land surface emissivity for Landsat TM6. Remote Sens Land Resour 3:28-32 (in Chinese)

Rosenzweig C, Solecki WD, Parshall L, Chopping M, Pope G, Goldberg R (2005) Characterizing the urban heat island in current and future climates in New Jersey. Global Environ Change B 6:51-62

Streutker DR (2003) Satellite-measured growth of the urban heat island of Houston, Texas. Remote Sens Environ 85:282-289

Twine TE, Kustas WP, Norman JM, Cook DR, Houser PR, Meyers TP, Prueger JH, Starks PJ, Wesely ML (2000) Correcting eddy-covariance flux underestimates over grassland. Agric For Meteorol 103:279-300

Voogt JA, Oke TR (2003) Thermal remote sensing of urban climates. Remote Sens Environ 86:370-384

Wan ZM, Zhang YL, Zhang QC, Li ZL (2002) Validation of the land-surface temperature products retrieved from Terra moderate resolution imaging spectroradiometer data. Remote Sens Environ 83:163-180
Wang Y, Hu F (2006) Variations of the urban heat island in summer of the recent 10 years over Beijing and its environment effect. Chin J Geophys-ch 49(1):61-68

Wang X, Bian LG, Lu CG (2003) A study of characteristic parameters of atmospheric boundary layer over Beijing in urban and suburban area in Autumn. Clim Environ Res $8(4): 475-484$

Wang XX, Hu DS, Zhu QJ (2011) Comparison of infrared radiative temperatures from two scales on different land surfaces. J Guangxi Norm Univ 29(2):1-4 (in Chinese)

Webb EK, Pearman GI, Leuning R (1980) Correction of flux measurements for density effects due to heat and water vapour transfer. Q J Roy Meteorol Soc 106:85-100

Weng QH, Lu DS, Schubring J (2004) Estimation of land surface temperature-vegetation abundance relationship for urban heat island studies. Remote Sens Environ 89(4):467-483

Weng Q, Hu X, Quattrochi DA, Liu H (2013) Assessing intraurban surface energy fluxes using remotely sensed ASTER imagery and routine meteorological data: a case study in Indianapolis, U.S.A. IEEE J Sel Top Appl 99:1-12

Wu JG (2010) Urban sustainability: an inevitable goal of landscape research. Landscape Ecol 25:1-4

Wu JG (2013) Landscape sustainability science: ecosystem services and human well-being in changing landscape. Landscape Ecol 28:999-1023

Wu JG (2014) Urban ecology and sustainability: the state-ofthe-science and future directions. Landsc Urban Plan. doi:10.1016/j.landurbplan.2014.01.018

Wu JG, David JL (2002) A spatially explicit hierarchical approach to modeling complex ecological systems: theory and applications. Ecol Model 153(1):7-26

Xiao RB, Ouyang ZY, Zheng H, Li WF, Schienke EW, Wang XK (2007) Spatial pattern of impervious surfaces and their impacts on land surface temperature in Beijing. China. J Environ Sci 19(2):250-256

Xiao RB, Weng QH, Ouyang ZY, Li WF, Schienke EW, Zhang ZM (2008) Land surface temperature variation and major actors in Beijing, China. Photogramm Eng Rem Sens 74(4):451-461

Xu YY, Liu SH, Hu F (2009) Influence of Beijing urbanization on the characteristics of atmospheric boundary layer. J Atmos Sci-ch 3(4):859-867

Yang P, Liu WD, Hou W (2011) The trend and inter-decadal evolution of extreme temperature events in Beijing area. J Catastrophology 26(1):60-64

Yu SQ, Bian LG, Lin XC (2005) Changes in the spatial scale of Beijing UHI and urban development. Sci China Ser D 48(II):116-127

Zhang C, Tian HQ, Pan SF, Liu ML, Lockaby G, Schilling EB, Stanturf J (2008) Effects of forest regrowth and urbanization on ecosystem carbon storage in a rural-urban gradient in the Southeastern United States. Ecosystems 11:1211-1222

Zhang C, Wu JG, Grimm BN, McHale M, Buyantuyev A (2013) A hierarchical patch mosaic ecosystem model for urban landscapes: model development and evaluation. Ecol Model 250:81-100

Zheng G, Lu M, Zhang T, Liu G, Ke C (2010) The impact of difference of land surface emissivity on the land surface 
temperature retrieval of Jinan City. J ShanDong JianZhu Univ 25(5):519-523 (in Chinese)

Zhou J, Li J, Zhang LX (2009) Validation of algorithms for retrieving land surface temperature based on MODIS data: a case study in the upper reaches of Heihe River. J Glaciol Geocryol 31(2):239-246

Zhou W, Huang G, Cadenasso ML (2011a) Does spatial configuration matter? Understanding the effects of land cover pattern on land surface temperature in urban landscapes. Landsc Urban Plan 102:54-63

Zhou W, Qian Y, Li X, Li W, Han L (2011b) Relationships between land cover and the surface urban heat island: seasonal variability and effects of spatial and thematic resolution of land cover data on predicting land surface temperatures. Landscape Ecol 29(1):153-167 